\title{
Review Article \\ Hypoglycemia Induced by Insulin as a Triggering Factor of Cognitive Deficit in Diabetic Children
}

\author{
Vanessa Rodrigues Vilela, Any de Castro Ruiz Marques, \\ Christiano Rodrigues Schamber, and Roberto Barbosa Bazotte \\ Department of Pharmacology and Therapeutics, State University of Maringá, 87020-900 Maringá, PR, Brazil \\ Correspondence should be addressed to Roberto Barbosa Bazotte; rbbazotte@uem.br
}

Received 28 December 2013; Accepted 18 February 2014; Published 23 March 2014

Academic Editors: G. B. Melis and A. Schreiber

Copyright (c) 2014 Vanessa Rodrigues Vilela et al. This is an open access article distributed under the Creative Commons Attribution License, which permits unrestricted use, distribution, and reproduction in any medium, provided the original work is properly cited.

\begin{abstract}
This paper provides an overview of insulin-induced hypoglycemia as a triggering factor of cognitive deficit in children with type 1 diabetes mellitus. For this purpose, databases from 1961 to 2013 were used with the objective of detecting the primary publications that address the impact of hypoglycemia on cognitive performance of diabetic children. The results obtained from experimental animals were excluded. The majority of studies demonstrated that the cognitive deficit in diabetic children involves multiple factors including duration, intensity, severity, and frequency of hypoglycemia episodes. Additionally, age at the onset of type 1 diabetes also influences the cognitive performance, considering that early inception of the disease is a predisposing factor for severe hypoglycemia. Furthermore, the results suggest that there is a strong correlation between brain damage caused by hypoglycemia and cognitive deterioration. Therefore, a more cautious follow-up and education are needed to impede and treat hypoglycemia in children with diabetes mellitus.
\end{abstract}

\section{Introduction}

The main objective in treatment of diabetes is to reach glycemic values which are the closest possible to those found in nondiabetic patients. The absence of a rigorous control of glycemia predisposes the patient to a series of chronic complications that include nephropathy, retinopathy, neuropathy, myocardial infarct, cerebrovascular accident, and peripheral vascular disease.

During insulin therapy, one of the most common adverse reactions is hypoglycemia. In general, during hypoglycemia there is an accentuated release of adrenaline from the adrenal glands, leading to autonomic symptoms: sudoresis, tremors, tachycardia, facial flush, and other symptoms. Besides the autonomic symptoms, there may also be symptoms linked to the lack of glucose in the brain (neuroglycopenia): vertigo, confusion, exhaustion, weakness, headaches, inappropriate behavior, which may be confused with drunkenness, lack of attention, vision abnormalities, convulsions similar to epilepsy, and coma [1].
The assessment and correction of hypoglycemia are indicated only for patients who present with Whipple's triad: signs and symptoms consistent with hypoglycemia, glycemia $<70 \mathrm{mg} / \mathrm{dL}$, and improvement or resolution of symptomatology after elevation of glycemia.

It is interesting to note that when hypoglycemia episodes are repeated in short periods of time, there is a loss of perception of the symptoms of hypoglycemia [2-5]. This phenomenon, also present in children [6,7], which may be detected from the moment of the second episode of hypoglycemia $[8,9]$, has mechanisms which are not yet completely understood [10] and may disappear as adjustments in treatment to avoid the occurrence of new episodes of hypoglycemia [11, 12]. However, if there is no correction, there may be increased frequency, intensity, and duration of hypoglycemia considering that the return of perception depends on the appearance of a glycemic value lower than when the previous episode occurred [13]. Another important aspect related to loss of perception of hypoglycemia is the possibility that the patients with a better control of their 
glycemia (lower values for a prolonged time) have a greater tendency to suffer severe hypoglycemia [14].

When the hypoglycemia is intense (mental confusion, loss of consciousness, convulsions, and/or coma) and the patient needs the help of another person to recover from this condition, hypoglycemia is considered severe.

Severe hypoglycemia occurs very frequently in patients submitted to insulin therapy $[15,16]$. It is interesting to observe that when the reports of severe hypoglycemia by the patient and close family members are compared, it can be noted that the patient detects later [17] and reports a lower number of severe hypoglycemia episodes [18].

Thus, considering that the brain uses glucose as a source of energy, hypoglycemia could cause alterations in brain activity $[19,20]$ and neuronal death in more severe cases, justifying the possibility of correlation between hypoglycemia and cognitive alterations [21].

The term cognition refers to mental processes (thought, memory, learning, intelligence, reasoning, attention, decision-making, visual perception, motor coordination, etc.) that the individual uses to acquire and manage information [22]. Therefore, we consider cognitive alterations to be the conditions in which one or more previously described mental processes come to be altered.

The cognitive alterations that can occur during hypoglycemia are not caused by the increased release of glucagon, adrenalin, noradrenalin, GH, and cortisol [23] nor even by excess insulin [24]. On the other hand, cognitive alterations may occur regardless of hypoglycemia, in situations of sleep deprivation [25], hypoglycemia induced by fasting [26], and hyperglycemia [27] and in children of mothers who presented with gestational diabetes [28].

It is also important to emphasize that there is no doubt as to the fact that cognitive alterations occur during insulin-induced hypoglycemia [29-47]. Cognitive alterations are detected even before the patient's perception of his/her condition of hypoglycemia $[48,49]$ and are heterogeneous even for patients submitted to insulin-induced hypoglycemia under controlled conditions [50-52]. Additionally, cognitive alterations suffer the influence of factors such as age [15-53], consumption of alcohol [54] or caffeine [55], alanine administration [56], prolonged fasting [57], presence of microvascular damage [58], and degree of hypoglycemia [59]. Another aspect to be considered is the cognitive function to be evaluated, since in the same individual there may be cognitive alterations in some tests and not in others $[43,60]$. However, whether the occurrence of recurring episodes of insulin-induced hypoglycemia could cause permanent cognitive alterations is still unknown.

Therefore, based on the assumption that hypoglycemia would generate brain damage, it becomes necessary to know the factors related to hypoglycemia in triggering cognitive deficit. Nevertheless, the answer to this question is not simple since scientific literature pertaining to this theme is heterogeneous, particularly as to the different measuring methods for cognitive alterations. Therefore, it is necessary to analyze each case carefully, aiming at establishing the participation of factors related to hypoglycemia in the development of cognitive deficit, especially in children submitted to insulin therapy, since they are more susceptible to hypoglycemia.

\section{Hypoglycemia as a Limiting Factor for Reaching Desirable Levels of Glycemia}

Two important multicenter studies, the Diabetes Control and Complications Trial (DCCT) and the United Kingdom Prospective Diabetes Study (UKPDS), demonstrated the benefits gained with rigorous glycemic control in the treatment of diabetes. The DCCT [61] demonstrated that the maintenance of glycemia close to normal levels during intensive insulin therapy reduces the incidence and seriousness of chronic complications in type 1 diabetes. The UKPDS study [62] also demonstrated similar results in the treatment of type 2 diabetes.

However, in the DCCT trial [61], the patients presented with three times as many episodes of hypoglycemia relative to conventional therapy. In the UKPDS [62], the incidence of hypoglycemia in type 2 diabetic patients rose from 15 to $30 \%$ relative to conventional therapy. Therefore, the risk of hypoglycemia and its consequences represent the main limiting factor as to the effort in seeking an ideal glycemic control [63-66].

In general, the risk of hypoglycemia is greater when one compares insulin therapy with the insulin secretagogues (sulphonylureas, mitiglinides, diethyl-dipeptidase 4 inhibitors, or GLP-1 agonists) and therefore the risk of cognitive compromise will always be greater when insulin is compared to other antidiabetic agents.

\section{Neonatal Hypoglycemia as a Possible Triggering Factor of Cerebral Damage and Cognitive Deficit}

The earlier the appearance of hypoglycemia episodes, the greater the possibility of brain damage and cognitive compromise. According to this observation, brain damage and cognitive deficit were associated with neonatal hypoglycemia: neonatal encephalopathy [67], lesion of the occipital lobe and cortex [68-70], and reduction of the circumference of the head [71]. According to these studies, cognitive deficit has been described in children with a history of neonatal hypoglycemia [72].

Neonatal hypoglycemia is caused by congenital hyperinsulinism that can extend hypoglycemic episodes beyond the neonatal period and is also strongly associated with brain damage and deficit in neurological development [73].

Therefore, there is greater predisposition towards brain damage at a structural and functional level in children who presented with early hypoglycemia since the episodes occur at a crucial moment in brain development. Additionally, we should consider that the younger the age, the greater the difficulty in verbally expressing symptoms, which makes them more vulnerable to the consequences of hypoglycemia [74].

It should be pointed out that the situations described in this section do not involve the administration of insulin and 
that neonatal diabetes is extremely rare, and its treatment, in general, does not involve insulin therapy $[75,76]$. For these reasons, hypoglycemia associated with the administration of insulin and its potential as a trigger for brain damage and cognitive deficit in children will be covered more specifically in the next section of this review.

\section{Insulin-Induced Hypoglycemia (IIH) as a Possible Triggering Factor of Cerebral Damage and Cognitive Deficit in Children}

The first aspect to be pointed out is that the earlier the IIH episodes, the greater the risk of brain damage and cognitive deficit. According to this affirmation, it was noted that cognitive deficit is more evident in children with a history of severe IIH and who presented with the disease at less than 5 years of age [77-80].

On the other hand, risk of brain damage also extends to adults, since it was noted in these patients that hypoglycemic coma induced by insulin causes neuronal loss of white and grey matter of the telencephalon [81] and global brain atrophy [82]. Moreover, it is important to consider that, regardless of the occurrence of $I I H$, adult patients with type 1 diabetes in which the disease appeared at an age under 7 years presented with greater incidence of brain atrophy and intellectual performance relative to those in whom type 1 diabetes appeared at a later phase [83].

Another factor that contributes towards cognitive deficit is the greater frequency of severe $\mathrm{IIH}$ episodes [78-84], particularly when the patient presents with a history of convulsions [85]. In this aspect, it must be taken into consideration that cognitive alterations are more intense in children who present with a greater frequency of severe IIH [86].

Although the majority of studies cover separately the precociousness of type 1 diabetes appearance [83-87], the occurrence of episodes of severe IIH [87] and their frequency [78], and the intensity of the hypoglycemia [85], these four factors are strongly interconnected as the early appearance of type 1 diabetes leads to an earlier introduction of insulin therapy, increasing the possibility of the IIH episodes occurring more frequently and with greater intensity. Additionally, other factors that also increase the risk of IIH in children with type 1 diabetes should be considered, duration of type 1 diabetes, alterations in dose and type of insulin, insulin injection regime [88], and exercise [89], and belong to disadvantaged minorities [90].

\section{IIH as a Possible Triggering Factor of Cerebral Damage and Cognitive Deficit in Children: An Issue Not yet Totally Clear}

The first argument favorable to associating IIH with brain damage and cognitive deficit in children results from the fact that, in type 1 diabetic patients with a history of severe IIH, cognitive dysfunction is generally irreversible [91-97] and is caused by brain abnormalities [98-100]. For example, in adults, alterations in electric activity of the temporal lobe [101], cortical atrophy [102], and lesions of the left temporal lobe [103] were noted which would justify the lower performance of these patients in memory tests $[78,86,104]$ and other evaluations of cognitive function [105].

Therefore, the fact that hypoglycemia causes brain damage and cognitive deficit in adults significantly reinforces the argument presented by studies in children with type 1 diabetes on insulin therapy, the majority of whom suggest the existence of cognitive compromise associated with IIH [106]. Nevertheless, some clinical studies [107-118] contrast with this position, since no cognitive deficit was observed in association with IIH in children. However, we cannot ignore the fact that, in one of these scientific articles [109], there was follow-up of 1144 type 1 diabetic patients over the course of 18 years and no evidence of cognitive function decline was found associated with a history of severe IIH episodes. It must be emphasized that although this paper published in The New England Journal of Medicine contrasts in terms of results with the majority of clinical studies relative to the theme, the number of patients evaluated $(n=1144)$ and the period of follow-up (18 years) exceed the other studies presented in this review. Nonetheless, it should be pointed out that this study included only type 1 diabetic patients on insulin therapy between 13 and 39 years of age, and, as was mentioned earlier, the greatest risks of hypoglycemia and cognitive deficit would be present in children who presented with the disease at less than 5 years of age [77-80].

Lastly, although it is not the focus of this review, another variable to be considered is the possibility of hypoglycemic episodes occurring within a context of hyperglycemia resulting from inappropriate insulin treatment, since it must be considered that acute $[119,120]$ and chronic [121-124] hyperglycemia, gestational hyperglycemia [125], and glycemic variability $[126,127]$ can also contribute towards the reduction of cognitive performance, since the excess of glucose can lead to brain damage regardless of the occurrence of $\mathrm{IIH}$ [128]. Moreover, studies in laboratory animals suggest that hyperglycemia after hypoglycemia, a condition frequent in poorly controlled diabetes, would lead to more neuronal death than isolated hypoglycemia [129].

\section{Conclusion}

Most clinical studies suggest that frequent and severe episodes of IIH would hinder learning in children [123, 130] and in some situations this is associated with dead-in-bed syndrome in type 1 diabetic patients [131]. Therefore, it is important to intensify monitoring [132] and education of the child with type 1 diabetes submitted to insulin therapy, seeking to reduce the risks of hypoglycemia, particularly nocturnal hypoglycemia [2], hypoglycemia associated with exercise [133], and IIH during pregnancy [134].

The fact that needs to be taken into consideration is that children have a greater risk of hypoglycemia relative to adults, presenting greater sensitivity to the dose of insulin administered and greater daily variability in terms of calorie ingestion and physical activity. 


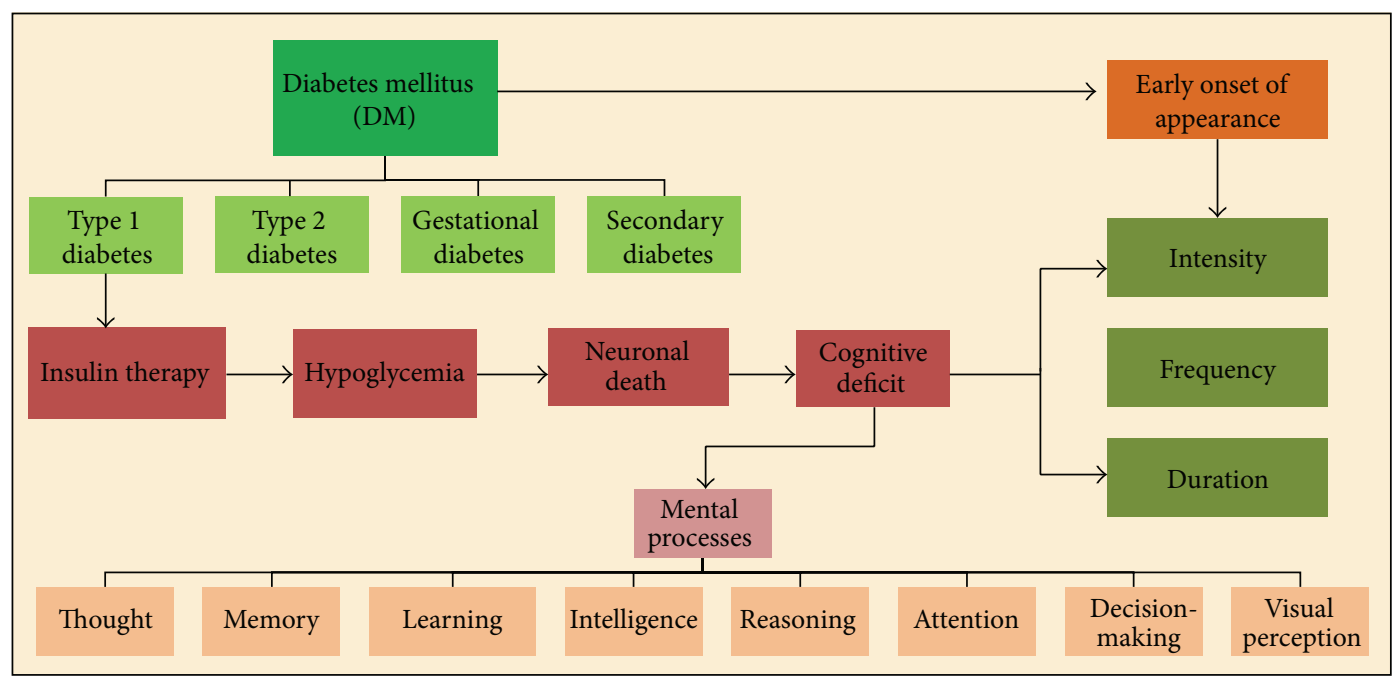

FIGURE 1: Insulin-induced hypoglycemia and its correlations with neuronal death and cognitive alterations.

The association between the history of IIH and cognitive deficit involves multiple factors, especially intensity, frequency, and duration of IIH. Additionally, it was noted that the earlier the appearance of diabetes in children, the greater the tendency towards hypoglycemia episodes and consequently the greater the risk of deterioration of cognitive function.

Brain damage caused by hypoglycemia episodes is a factor of structural and functional nature that triggers cognitive deficit. Another relevant aspect is that among the brain areas affected the hippocampus would be among the most sensitive, which would explain the fact that memory is one of the most affected cognitive functions.

A general view of the principal aspects covered in this review includes type 1 diabetes, hypoglycemia, neuronal death, and cognitive deficit, as well as the influence of factors such as precociousness in the appearance of type 1 diabetes, intensity, frequency, and duration of $\mathrm{IIH}$, which are all summarized in Figure 1.

\section{Conflict of Interests}

The authors declare that there is no conflict of interests regarding the publication of this paper.

\section{Acknowledgments}

This research is supported by CNPq (477249/2011-6), Araucaria Foundation, and PRONEX (24861/2012).

\section{References}

[1] B. M. Frier, "Morbidity of hypoglycemia in type 1 diabetes," Diabetes Research and Clinical Practice, vol. 65, pp. S47-S52, 2004.

[2] C. G. Fanelli, D. S. Paramore, T. Hershey et al., "Impact of nocturnal hypoglycemia on hypoglycemic cognitive dysfunction in type 1 diabetes," Diabetes, vol. 47, no. 12, pp. 1920-1927, 1998.
[3] A. E. Gold, K. M. MacLeod, I. J. Deary, and B. M. Frier, "Hypoglycemia-induced cognitive dysfunction in diabetes mellitus: effect of hypoglycemia unawareness," Physiology and Behavior, vol. 58, no. 3, pp. 501-511, 1995.

[4] B. Schultes, W. Kern, K. Oltmanns et al., "Differential adaptation of neurocognitive brain functions to recurrent hypoglycemia in healthy men," Psychoneuroendocrinology, vol. 30, no. 2, pp. 149$161,2005$.

[5] F. Sundberg and G. Forsander, "Detection and treatment efficacy of hypoglycemic events in the everyday life of children younger than 7 yr," Pediatric Diabetes, vol. 15, no. 1, pp. 34-40, 2014.

[6] L. Barkai, I. Vámosi, and K. Lukács, "Prospective assessment of severe hypoglycaemia in diabetic children and adolescents with impaired and normal awareness of hypoglycaemia," Diabetologia, vol. 41, no. 8, pp. 898-903, 1998.

[7] T. T. Ly, P. H. Gallego, E. A. Davis, and T. W. Jones, "Impaired awareness of hypoglycemia in a population-based sample of children and adolescents with type 1 diabetes," Diabetes Care, vol. 32, no. 10, pp. 1802-1806, 2009.

[8] B. Fruehwald-Schultes, J. Born, W. Kern, A. Peters, and H. L. Fehm, "Adoptation of cognitive function to hypoglycemia in healthy men," Diabetes Care, vol. 23, no. 8, pp. 1059-1066, 2000.

[9] M. J. Mellman, M. R. Davis, M. Brisman, and H. Shamoon, "Effect of antecedent hypoglycemia on cognitive function and on glycemic thresholds for counterregulatory hormone secretion in healthy humans," Diabetes Care, vol. 17, no. 3, pp. 183$188,1994$.

[10] C. M. Reno, M. Litvin, A. L. Clark, and S. J. Fisher, "Defective counterregulation and hypoglycemia unawareness in diabetes: mechanisms and emerging treatments," Endocrinology and Metabolism Clinics of North America, vol. 42, pp. 15-38, 2013.

[11] S. O. Bakatselos, "Hypoglycemia unawareness," Diabetes Research and Clinical Practice, vol. 93, no. 1, pp. S92-S96, 2011.

[12] C. G. Fanelli, L. Epifano, A. M. Rambotti et al., "Meticulous prevention of hypoglycemia normalizes the glycemic thresholds and magnitude of most of neuroendocrine responses to, symptoms of, and cognitive function during hypoglycemia in intensively treated patients with short-term IDDM," Diabetes, vol. 42, no. 11, pp. 1683-1689, 1993. 
[13] J. Peczyńska, M. Urban, B. Głowińska, and B. Florys, "How often does decreased consciousness of hypoglycaemia occur in children and adolescents with diabetes type 1 and what are its consequences?" Endokrynologia, Diabetologia i Choroby Przemiany Materii Wieku Rozwojowego, vol. 10, no. 1, pp. 9-14, 2004.

[14] A. Maran, J. Lomas, I. A. Macdonald, and S. A. Amiel, "Lack of preservation of higher brain function during hypoglycaemia in patients with intensively-treated IDDM," Diabetologia, vol. 38, no. 12, pp. 1412-1418, 1995.

[15] C. Bali, C. Gurdet, and K. Irsigler, "Retrospective analysis of the incidence of severe hypoglycemia in 458 type 1 diabetic patients," Acta Medica Austriaca, vol. 24, no. 5, pp. 165-169, 1997.

[16] E. W. M. T. ter Braak, A. M. M. F. Appelman, M. F. D. E. van Laak, R. P. Stolk, T. W. van Haeften, and D. W. Erkelens, "Clinical characteristics of type 1 diabetic patients with and without severe hypoglycemia," Diabetes Care, vol. 23, no. 10, pp. 1467-1471, 2000.

[17] T. M. Rintala, E. Paavilainen, and P. Åstedt-Kurki, "Everyday living with diabetes described by family members of adult people with type 1 diabetes," International Journal of Family Medicine, vol. 2013, Article ID 967872, 8 pages, 2013.

[18] H. V. Jørgensen, U. Pedersen-Bjergaard, Å. K. Rasmussen, and K. Borch-Johnsen, "The impact of severe hypoglycemia and impaired awareness of hypoglycemia on relatives of patients with type 1 diabetes," Diabetes Care, vol. 26, no. 4, pp. 1106-1109, 2003.

[19] D. Kerr, J. C. Stanley, M. Barron, R. Thomas, B. A. Leatherdale, and J. Pickard, "Symmetry of cerebral blood flow and cognitive responses to hypoglycaemia in humans," Diabetologia, vol. 36, no. 1, pp. 73-78, 1993.

[20] H. G. O. M. Smid, B. G. Trümper, G. Pottag et al., "Differentiation of hypoglycaemia induced cognitive impairments. An electrophysiological approach," Brain, vol. 120, no. 6, pp. 10411056, 1997.

[21] S. Gataullina, P. de Lonlay, G. Dellatolas et al., "Topography of brain damage in metabolic hypoglycaemia is determined by age at which hypoglycaemia occurred," Developmental Medicine \& Child Neurology, vol. 55, no. 2, pp. 162-166, 2013.

[22] C. G. Morris and A. A. Maisto, Cognição e capacidades mentais. Introdução a Psicologia, Prentice Hall, São Paulo, Brazil, 2004.

[23] D. Kerr, M. P. Diamond, W. V. Tamborlane, S. Kerr, and R. S. Sherwin, "Influence of counterregulatory hormones, independently of hypoglycaemia, on cognitive function, warning symptoms and glucose kinetics," Clinical Science, vol. 85, no. 2, pp. 197-101, 1993.

[24] M. A. Reger, G. S. Watson, W. H. Frey II et al., "Effects of intranasal insulin on cognition in memory-impaired older adults: modulation by APOE genotype," Neurobiology of Aging, vol. 27, no. 3, pp. 451-458, 2006.

[25] G. Owen, H. Turley, and A. Casey, "The role of blood glucose availability and fatigue in the development of cognitive impairment during combat training," Aviation Space and Environmental Medicine, vol. 75, no. 3, pp. 240-246, 2004.

[26] P. Wiesli, B. Schwegler, B. Schmid, G. A. Spinas, and C. Schmid, "Mini-Mental State Examination is superior to plasma glucose concentrations in monitoring patients with suspected hypoglycaemic disorders during the 72-hour fast," European Journal of Endocrinology, vol. 152, no. 4, pp. 605-610, 2005.

[27] D. Kelly, J. K. Hamilton, and M. C. Riddell, "Blood glucose levels and performance in a sports camp for adolescents with type 1 diabetes mellitus: a field study," International Journal of Pediatrics, vol. 2010, Article ID 216167, 8 pages, 2010.

[28] T. DeBoer, S. Wewerka, P. J. Bauer, M. K. Georgieff, and C. A. Nelson, "Explicit memory performance in infants of diabetic mothers at 1 year of age," Developmental Medicine \& Child Neurology, vol. 47, no. 8, pp. 525-531, 2005.

[29] J. P. Bremer, M. Baron, H. Peters et al., "Hormonal, subjective, and neurocognitive responses to brief hypoglycemia in postmenopausal women and age-matched men with type 2 diabetes mellitus," Metabolism: Clinical and Experimental, vol. 55, no. 3, pp. 331-338, 2006.

[30] D. J. Cox, L. A. Gonder-Frederick, B. P. Kovatchev, D. M. Julian, and W. L. Clarke, "Progressive hypoglycemia's impact on driving simulation performance: occurrence, awareness, and correction," Diabetes Care, vol. 23, no. 2, pp. 163-170, 2000.

[31] M. T. Draelos, A. M. Jacobson, K. Weinger et al., "Cognitive function in patients with insulin-dependent diabetes mellitus during hyperglycemia and hypoglycemia," American Journal of Medicine, vol. 98, no. 2, pp. 135-144, 1995.

[32] M. L. Evans, A. Pernet, J. Lomas, J. Jones, and S. A. Amiel, "Delay in onset of awareness of acute hypoglycemia and of restoration of cognitive performance during recovery," Diabetes Care, vol. 23, no. 7, pp. 893-897, 2000.

[33] F. M. E. Ewing, I. J. Deary, R. J. McCrimmon, M. W. J. Strachan, and B. M. Frier, "Effect of acute hypoglycemia on visual information processing in adults with type 1 diabetes mellitus," Physiology and Behavior, vol. 64, no. 5, pp. 653-660, 1998.

[34] A. J. Graveling, R. E. Warren, and B. M. Frier, "Hypoglycaemia and driving in people with insulin-treated diabetes: adherence to recommendations for avoidance," Diabetic Medicine, vol. 21, no. 9, pp. 1014-1019, 2004.

[35] C. G. Fanelli, S. Pampanelli, L. Epifano et al., "Relative roles of insulin and hypoglycaemia on induction of neuroendocrine responses to, symptoms of, and deterioration of cognitive function in hypoglycaemia in male and female humans," Diabetologia, vol. 37, no. 8, pp. 797-807, 1994.

[36] C. G. Fanelli, S. Pampanelli, F. Porcellati et al., "Rate of fall of blood glucose and physiological responses of counterregulatory hormones, clinical symptoms and cognitive function to hypoglycaemia in type I diabetes mellitus in the postprandial state," Diabetologia, vol. 46, no. 1, pp. 53-64, 2003.

[37] S. Gschwend, C. Ryan, J. Atchison, S. Arslanian, and D. Becker, "Effects of acute hyperglycemia on mental efficiency and counterregulatory hormones in adolescents with insulindependent diabetes mellitus," The Journal of Pediatrics, vol. 126, no. 2, pp. 178-184, 1995.

[38] R. Lobmann, H. G. O. M. Smid, G. Pottag, K. Wagner, H.J. Heinze, and H. Lehnert, "Impairment and recovery of elementary cognitive function induced by hypoglycemia in type1 diabetic patients and healthy controls," Journal of Clinical Endocrinology and Metabolism, vol. 85, no. 8, pp. 2758-2766, 2000.

[39] R. G. Hoffman, D. J. Speelman, D. A. Hinnen, K. L. Conley, R. A. Guthrie, and R. K. Knapp, "Changes in cortical functioning with acute hypoglycemia and hyperglycemia in type I diabetes," Diabetes Care, vol. 12, no. 3, pp. 193-197, 1989.

[40] D. Kerr, M. Reza, N. Smith, and B. A. Leatherdale, "Importance of insulin in subjective, cognitive, and hormonal responses to hypoglycemia in patients with IDDM," Diabetes, vol. 40 , no. 8 , pp. 1057-1062, 1991. 
[41] E. Ipp and B. Forster, "Sparing of cognitive function in mild hypoglycemia: dissociation from the neuroendocrine response," Journal of Clinical Endocrinology and Metabolism, vol. 65, no. 4, pp. 806-810, 1987.

[42] T. Lingenfelser, D. Overkamp, W. Renn et al., "Cognitive and psychomotor function during severe insulin-induced hypoglycaemia in insulin-dependent diabetic patients," Neuropsychobiology, vol. 25, no. 3, pp. 161-165, 1992.

[43] V. McAulay, I. J. Deary, S. C. Ferguson, and B. M. Frier, "Acute hypoglycemia in humans causes attentional dysfunction while nonverbal intelligence is preserved," Diabetes Care, vol. 24, no. 10, pp. 1745-1750, 2001.

[44] A. J. Sommerfield, I. J. Deary, V. McAulay, and B. M. Frier, "Short-term, delayed, and working memory are impaired during hypoglycemia in individuals with type 1 diabetes," Diabetes Care, vol. 26, no. 2, pp. 390-396, 2003.

[45] M. W. J. Strachan, I. J. Deary, F. M. E. Ewing, and B. M. Frier, "Recovery of cognitive function and mood after severe hypoglycemia in adults with insulin-treated diabetes," Diabetes Care, vol. 23, no. 3, pp. 305-312, 2000.

[46] M. W. J. Strachan, I. J. Deary, F. M. E. Ewing, S. S. C. Ferguson, M. J. Young, and B. M. Frier, "Acute hypoglycemia impairs the functioning of the central but not peripheral nervous system," Physiology and Behavior, vol. 72, no. 1-2, pp. 83-92, 2001.

[47] K. Weinger, B. T. Kinsley, C. J. Levy et al., "The perception of safe driving ability during hypoglycemia in patients with type 1 diabetes mellitus," American Journal of Medicine, vol. 107, no. 3, pp. 246-253, 1999.

[48] P. de Feo, V. Gallai, G. Mazzotta et al., "Modest decrements in plasma glucose concentration cause early impairment in cognitive function and later activation of glucose counterregulation in the absence of hypoglycemic symptoms in normal man," The Journal of Clinical Investigation, vol. 82, no. 2, pp. 436-444, 1988.

[49] S. Pramming, B. Thorsteinsson, A. Theilgaard, E. M. Pinner, and C. Binder, "Cognitive function during hypoglycaemia in type I diabetes mellitus," British Medical Journal, vol. 292, no. 6521, pp. 647-650, 1986.

[50] D. J. Cox, L. A. Gonder-Frederick, D. B. Schroeder, P. E. Cryer, and W. L. Clarke, "Disruptive effects of acute hypoglycemia on speed of cognitive and motor performance," Diabetes Care, vol. 16, no. 10, pp. 1391-1392, 1993.

[51] L. A. Gonder-Frederick, D. J. Cox, N. R. Driesen, C. M. Ryan, and W. L. Clarke, "Individual differences in neurobehavioral disruption during mild and moderate hypoglycemia in adults with IDDM," Diabetes, vol. 43, no. 12, pp. 1407-1412, 1994.

[52] C. M. Ryan, J. Atchison, S. Puczynski, M. Puczynski, S. Arslanian, and D. Becker, "Mild hypoglycemia associated with deterioration of mental efficiency in children with insulindependent diabetes mellitus," The Journal of Pediatrics, vol. 117, no. 1, pp. 32-38, 1990.

[53] R. J. McCrimmon, A. E. Gold, I. J. Deary, C. J. H. Kelnar, and B. M. Frier, "Symptoms of hypoglycemia in children with IDDM," Diabetes Care, vol. 18, no. 6, pp. 858-861, 1995.

[54] E. H. Cheyne, R. S. Sherwin, M. J. Lunt, D. A. Cavan, P. W. Thomas, and D. Kerr, "Influence of alcohol on cognitive performance during mild hypoglycaemia; implications for type 1 diabetes," Diabetic Medicine, vol. 21, no. 3, pp. 230-237, 2004.

[55] J. M. Watson, E. J. E. Jenkins, P. Hamilton, M. J. Lunt, and D. Kerr, "Influence of caffeine on the frequency and perception of hypoglycemia in free-living patients with type 1 diabetes," Diabetes Care, vol. 23, no. 4, pp. 455-459, 2000.
[56] M. L. Evans, D. Hopkins, I. A. Macdonald, and S. A. Amiel, "Alanine infusion during hypoglycaemia partly supports cognitive performance in healthy human subjects," Diabetic Medicine, vol. 21, no. 5, pp. 440-446, 2004.

[57] S. Fourest-Fontecave, U. Adamson, P. E. Lins, B. Ekblom, C. Sandahl, and L. Strand, "Mental alertness in response to hypoglycaemia in normal man: the effect of 12 hours and 72 hours of fasting," Diabetes \& Metabolism, vol. 13, no. 4, pp. 405410, 1987.

[58] A. M. Wessels, S. A. R. B. Rombouts, S. Simsek et al., "Microvascular disease in type 1 diabetes alters brain activation: a functional magnetic resonance imaging study," Diabetes, vol. 55, no. 2, pp. 334-340, 2006.

[59] M. A. Nauck, M. M. Heimesaat, K. Behle et al., "Effects of glucagon-like peptide 1 on counterregulatory hormone responses, cognitive functions, and insulin secretion during hyperinsulinemic, stepped hypoglycemic clamp experiments in healthy volunteers," Journal of Clinical Endocrinology and Metabolism, vol. 87, no. 3, pp. 1239-1246, 2002.

[60] C. S. Holmes, J. T. Hayford, J. L. Gonzalez, and J. A. Weydert, "A survey of cognitive functioning at different glucose levels in diabetic persons," Diabetes Care, vol. 6, no. 2, pp. 180-185, 1983.

[61] Diabetes Control and Complications Trial (DCCT) Research Group, "The effect of intensive treatment of diabetes on the development and progression of long-term complications in insulin-dependent diabetes mellitus," The New England Journal of Medicine, vol. 329, no. 14, pp. 977-986, 1993.

[62] UK Prospective Diabetes Study (UKPDS) Group, "Intensive blood-glucose control with sulphonylureas or insulin compared with conventional treatment and risk of complications in patients with type 2 diabetes (UKPDS 33)," The Lancet, vol. 352, no. 9131, pp. 837-853, 1998.

[63] M. N. Cooper, S. M. O'Connell, E. A. Davis, and T. W. Jones, “A population-based study of risk factors for severe hypoglycaemia in a contemporary cohort of childhood-onset type 1 diabetes," Diabetologia, vol. 56, no. 10, pp. 2164-2170, 2013.

[64] E. A. Davis, B. Keating, G. C. Byrne, M. Russell, and T. W. Jones, "Impact of improved glycaemic control on rates of hypoglycaemia in insulin dependent diabetes mellitus," Archives of Disease in Childhood, vol. 78, no. 2, pp. 111-115, 1998.

[65] S. R. Johnson, M. N. Cooper, E. A. Davis, and T. W. Jones, "Hypoglycaemia, fear of hypoglycaemia and quality of life in children with type 1 diabetes and their parents," Diabetic Medicine, vol. 30, no. 9, pp. 1126-1131, 2013.

[66] G. Maltoni, S. Zucchini, M. Scipione et al., "Severe hypoglycemic episodes: a persistent threat for children with type 1 diabetes mellitus and their families," Journal of Endocrinological Investigation, vol. 36, no. 8, pp. 617-621, 2013.

[67] E. W. Y. Tam, L. A. Haeusslein, S. L. Bonifacio et al., "Hypoglycemia is associated with increased risk for brain injury and adverse neurodevelopmental outcome in neonates at risk for encephalopathy," The Journal of Pediatrics, vol. 161, no. 1, pp. 8893, 2012.

[68] A. J. Barkovich, F. Al Ali, H. A. Rowley, and N. Bass, "Imaging patterns of neonatal hypoglycemia," American Journal of Neuroradiology, vol. 19, no. 3, pp. 523-528, 1998.

[69] P. M. Filan, T. E. Inder, F. J. Cameron, M. J. Kean, and R. W. Hunt, "Neonatal hypoglycemia and occipital cerebral injury," The Journal of Pediatrics, vol. 148, no. 4, pp. 552-555, 2006.

[70] E. W. Y. Tam, E. Widjaja, S. I. Blaser, D. L. MacGregor, P. Satodia, and A. M. Moore, "Occipital lobe injury and cortical visual 
outcomes after neonatal hypoglycemia," Pediatrics, vol. 122, no. 3, pp. 507-512, 2008.

[71] C. B. Duvanel, C.-L. Fawer, J. Colling, P. Hohlfeld, and J.M. Matthieu, "Long-term effects of neonatal hypoglycemia on brain growth and psychomotor development in small-forgestational-age preterm infants," The Journal of Pediatrics, vol. 134, no. 4, pp. 492-498, 1999.

[72] A. Lucas, R. Morley, and T. J. Cole, "Adverse neurodevelopmental outcome of moderate neonatal hypoglycaemia," British Medical Journal, vol. 297, no. 6659, pp. 1304-1308, 1988.

[73] K. Hussain, A. Aynsley-Green, and C. A. Stanley, "Medications used in the treatment of hypoglycemia due to congenital hyperinsulinism of infancy (HI)," Pediatric Endocrinology Reviews, vol. 2, no. 1, pp. 163-167, 2004.

[74] C. M. Ryan, "Does severe hypoglycaemia disrupt academic achievement in children with early onset diabetes?" Developmental Medicine \& Child Neurology, vol. 54, no. 5, pp. 393-394, 2012.

[75] J. Hamilton-Shield, "Overview of neonatal diabetes," Endocrine Development, vol. 12, pp. 12-23, 2007.

[76] S. Senniappan and K. Hussain, "An evaluation of growth hormone and IGF-1 responses in neonates with hyperinsulinaemic hypoglycaemia," International Journal of Endocrinology, vol. 2013, Article ID 638257, 5 pages, 2013.

[77] M. Bjørgaas, R. Gimse, T. Vik, and T. Sand, "Cognitive function in type 1 diabetic children with and without episodes of severe hypoglycaemia," Acta Paediatrica, vol. 86, no. 2, pp. 148-153, 1997.

[78] T. Hershey, D. C. Perantie, S. L. Warren, E. C. Zimmerman, M. Sadler, and N. H. White, "Frequency and timing of severe hypoglycemia affects spatial memory in children with type 1 diabetes," Diabetes Care, vol. 28, no. 10, pp. 2372-2377, 2005.

[79] J. F. Rovet, R. M. Ehrlich, and M. Hoppe, "Intellectual deficits associated with early onset of insulin-dependent diabetes mellitus in children," Diabetes Care, vol. 10, no. 4, pp. 510-515, 1987.

[80] J. F. Rovet, R. M. Ehrlich, D. Czuchta, and M. Akler, "Psychoeducational characteristics of children and adolescents with insulin-dependent diabetes mellitus," Journal of Learning Disabilities, vol. 26, no. 1, pp. 7-22, 1993.

[81] R. N. Auer, J. Hugh, E. Cosgrove, and B. Curry, "Neuropathologic findings in three cases of profound hypoglycemia," Clinical Neuropathology, vol. 8, no. 2, pp. 63-68, 1989.

[82] A. Akyol, N. Kiylioglu, O. Bolukbasi, E. Guney, and Y. Yurekli, "Repeated hypoglycemia and cognitive decline. A case report," Neuroendocrinology Letters, vol. 24, no. 1-2, pp. 54-56, 2003.

[83] S. C. Ferguson, A. Blane, J. Wardlaw et al., "Influence of an earlyonset age of type 1 diabetes on cerebral structure and cognitive function," Diabetes Care, vol. 28, no. 6, pp. 1431-1437, 2005.

[84] R. Hannonen, S. Tupola, T. Ahonen, and R. Riikonen, "Neurocognitive functioning in children with type-1 diabetes with and without episodes of severe hypoglycaemia," Developmental Medicine \& Child Neurology, vol. 45, no. 4, pp. 262-268, 2003.

[85] J. Rovet and M. Alvarez, "Attentional functioning in children and adolescents with IDDM," Diabetes Care, vol. 20, no. 5, pp. 803-810, 1997.

[86] T. Hershey, R. Lillie, M. Sadler, and N. H. White, "Severe hypoglycemia and long-term spatial memory in children with type 1 diabetes mellitus: a retrospective study," The Journal of the International Neuropsychological Society, vol. 9, no. 5, pp. 740750, 2003.
[87] T. T. Ly, M. Anderson, K. A. McNamara, E. A. Davis, and T. W. Jones, "Neurocognitive outcomes in young adults with earlyonset type 1 diabetes: a prospective follow-up study," Diabetes Care, vol. 34, no. 10, pp. 2192-2197, 2011.

[88] V. M. Wagner, M. Grabert, and R. W. Holl, "Severe hypoglycaemia, metabolic control and diabetes management in children with type 1 diabetes in the decade after the Diabetes Control and Complications Trial-a large-scale multicentre study," European Journal of Pediatrics, vol. 164, no. 2, pp. 73-79, 2005.

[89] P. Galassetti and M. C. Riddell, "Exercise and type 1 diabetes (T1DM)," Comprehensive Physiology, vol. 3, no. 3, pp. 1309-1336, 2013.

[90] E. Cengiz, D. Xing, J. C. Wong et al., "Severe hypoglycemia and diabetic ketoacidosis among youth with type 1 diabetes in the T1D Exchange clinic registry," Pediatric Diabetes, vol. 14, no. 6, pp. 447-454, 2013.

[91] I. J. Deary, J. R. Crawford, D. A. Hepburn, S. J. Langan, L. M. Blackmore, and B. M. Frier, "Severe hypoglycemia and intelligence in adult patients with insulin-treated diabetes," Diabetes, vol. 42, no. 2, pp. 341-344, 1993.

[92] A. E. Gold, I. J. Deary, R. W. Jones, J. P. O’Hare, J. P. D. Reckless, and B. M. Frier, "Severe deterioration in cognitive function and personality in five patients with long-standing diabetes: a complication of diabetes or a consequence of treatment?" Diabetic Medicine, vol. 11, no. 5, pp. 499-505, 1994.

[93] M. P. Golden, G. M. Ingersoll, C. J. Brack, B. A. Russell, J. C. Wright, and T. J. Huberty, "Longitudinal relationship of asymptomatic hypoglycemia to cognitive function in IDDM," Diabetes Care, vol. 12, no. 2, pp. 89-93, 1989.

[94] F. R. Kaufman, K. Epport, R. Engilman, and M. Halvorson, "Neurocognitive functioning in children diagnosed with diabetes before age 10 years," Journal of Diabetes and Its Complications, vol. 13, no. 1, pp. 31-38, 1999.

[95] S. J. Langan, I. J. Deary, D. A. Hepburn, and B. M. Frier, "Cumulative cognitive impairment following recurrent severe hypoglycaemia in adult patients with insulin-treated diabetes mellitus," Diabetologia, vol. 34, no. 5, pp. 337-344, 1991.

[96] J. F. Rovet and R. M. Ehrlich, "The effect of hypoglycemic seizures on cognitive function in children with diabetes: a 7year prospective study," The Journal of Pediatrics, vol. 134, no. 4, pp. 503-506, 1999.

[97] C. Sachon, A. Grimaldi, J. P. Digy, B. Pillon, B. Dubois, and F. Thervet, "Cognitive function, insulin-dependent diabetes and hypoglycaemia," Journal of Internal Medicine, vol. 231, no. 5, pp. 471-475, 1992.

[98] K. M. MacLeod, D. A. Hepburn, I. J. Deary et al., "Regional cerebral blood flow in IDDM patients: effects of diabetes and of recurrent severe hypoglycaemia," Diabetologia, vol. 37, no. 3, pp. 257-263, 1994.

[99] R. E. Warren and B. M. Frier, "Hypoglycaemia and cognitive function," Diabetes, Obesity and Metabolism, vol. 7, no. 5, pp. 493-503, 2005.

[100] T. Aye, A. L. Reiss, S. Kesler et al., “The feasibility of detecting neuropsychologic and neuroanatomic effects of type 1 diabetes in young children," Diabetes Care, vol. 34, no. 7, pp. 1458-1462, 2011.

[101] T. Brismar, L. Hyllienmark, K. Ekberg, and B.-L. Johansson, "Loss of temporal lobe beta power in young adults with type I diabetes mellitus," NeuroReport, vol. 13, no. 18, pp. 2469-2473, 2002 . 
[102] P. Perros, I. J. Deary, R. J. Sellar, J. J. K. Best, and B. M. Frier, "Brain abnormalities demonstrated by magnetic resonance imaging in adult IDDM patients with and without a history of recurrent severe hypoglycemia," Diabetes Care, vol. 20, no. 6, pp. 1013-1018, 1997.

[103] J. Chalmers, M. T. A. Risk, D. M. Kean, R. Grant, B. Ashworth, and I. W. Campbell, "Severe amnesia after hypoglycemia. Clinical, psychometric, and magnetic resonance imaging correlations," Diabetes Care, vol. 14, no. 10, pp. 922-925, 1991.

[104] T. Hershey, S. Craft, N. Bhargava, and N. H. White, "Memory and insulin dependent diabetes mellitus (IDDM): effects of childhood onset and severe hypoglycemia," The Journal of the International Neuropsychological Society, vol. 3, no. 6, pp. 509520, 1997.

[105] R. Wredling, S. Levander, U. Adamson, and P. E. Lins, "Permanent neuropsychological impairment after recurrent episodes of severe hypoglycaemia in man," Diabetologia, vol. 33, no. 3, pp. $152-157,1990$.

[106] C. M. Ryan, "Does moderately severe hypoglycemia cause cognitive dysfunction in children?" Pediatric Diabetes, vol. 5, no. 2, pp. 59-62, 2004.

[107] E. J. Austin and I. J. Deary, "Effects of repeated hypoglycemia on cognitive function: a psychometrically validated reanalysis of the Diabetes Control and Complications Trial data," Diabetes Care, vol. 22, no. 8, pp. 1273-1277, 1999.

[108] H. Chabriat, C. Sachon, M. Levasseur et al., "Brain metabolism after recurrent insulin induced hypoglycaemic episodes: a PET study," Journal of Neurology, Neurosurgery and Psychiatry, vol. 57, no. 11, pp. 1360-1365, 1994.

[109] DCCT/EDIC, "Long-term effect of diabetes and its treatment on cognitive function. The Diabetes Control and Complications Trial/Epidemiology of Diabetes Interventions and Complications (DCCT/EDIC) Study Research Group," The New England Journal of Medicine, vol. 356, pp. 1842-1852, 2007.

[110] S. C. Ferguson, A. Blane, P. Perros et al., "Cognitive ability and brain structure in type 1 diabetes: relation to microangiopathy and preceding severe hypoglycemia," Diabetes, vol. 52, no. 1, pp. 149-156, 2003.

[111] L. Kramer, P. Fasching, C. Madl et al., "Previous episodes of hypoglycemic coma are not associated with permanent cognitive brain dysfunction in IDDM patients on intensive insulin treatment," Diabetes, vol. 47, no. 12, pp. 1909-1914, 1998.

[112] E. Northam, S. Bowden, V. Anderson, and J. Court, "Neuropsychological functioning in adolescents with diabetes," Journal of Clinical and Experimental Neuropsychology, vol. 14, no. 6, pp. 884-900, 1992.

[113] P. Reichard, A. Berglund, A. Britz, S. Levander, and U. Rosenqvist, "Hypoglycaemic episodes during intensified insulin treatment: increased frequency but no effect on cognitive function," Journal of Internal Medicine, vol. 229, no. 1, pp. 9-16, 1991.

[114] P. Reichard, A. Britz, and U. Rosenqvist, "Intensified conventional insulin treatment and neuropsychological impairment," British Medical Journal, vol. 303, no. 6815, pp. 1439-1442, 1991.

[115] C. M. Ryan and T. M. Williams, "Effects of insulin-dependent diabetes on learning and memory efficiency in adults," Journal of Clinical and Experimental Neuropsychology, vol. 15, no. 5, pp. 685-700, 1993.

[116] C. M. Ryan, T. M. Williams, D. N. Finegold, and T. J. Orchard, "Cognitive dysfunction in adults with type 1 (insulindependent) diabetes mellitus of long duration: effects of recurrent hypoglycaemia and other chronic complications," Diabetologia, vol. 36, no. 4, pp. 329-334, 1993.
[117] S. K. Strudwick, C. Carne, J. Gardiner, J. K. Foster, E. A. Davis, and T. W. Jones, "Cognitive functioning in children with early onset type 1 diabetes and severe hypoglycemia," The Journal of Pediatrics, vol. 147, no. 5, pp. 680-685, 2005.

[118] T. Wysocki, M. A. Harris, N. Mauras et al., "Absence of adverse effects of severe hypoglycemia on cognitive function in schoolaged children with diabetes over 18 months," Diabetes Care, vol. 26, no. 4, pp. 1100-1105, 2003.

[119] D. J. Cox, B. P. Kovatchev, L. A. Gonder-Frederick et al., "Relationships between hyperglycemia and cognitive performance among adults with type 1 and type 2 diabetes," Diabetes Care, vol. 28, no. 1, pp. 71-77, 2005.

[120] R. E. Warren, I. J. Deary, and B. M. Frier, "The symptoms of hyperglycaemia in people with insulin-treated diabetes: classification using principal components analysis," Diabetes/Metabolism Research and Reviews, vol. 19, no. 5, pp. 408414, 2003.

[121] M. Ack, I. Miller, and W. Weil, "Intelligence of children with diabetes mellitus," Pediatrics, vol. 28, pp. 764-770, 1961.

[122] A. M. A. Brands, G. J. Biessels, E. H. F. de Haan, L. J. Kappelle, and R. P. C. Kessels, "The effects of type 1 diabetes on cognitive performance: a meta-analysis," Diabetes Care, vol. 28, no. 3, pp. 726-735, 2005.

[123] M. A. Fox, R. S. Chen, and C. S. Holmes, "Gender differences in memory and learning in children with insulin-dependent diabetes mellitus (IDDM) over a 4-year follow-up interval," Journal of Pediatric Psychology, vol. 28, no. 8, pp. 569-577, 2003.

[124] E. A. Northam, P. J. Anderson, R. Jacobs, M. Hughes, G. L. Warne, and G. A. Werther, "Neuropsychological profiles of children with type 1 diabetes 6 years after disease onset," Diabetes Care, vol. 24, no. 9, pp. 1541-1546, 2001.

[125] R. C. Temple, M. Hardiman, M. Pellegrini, L. Horrocks, and M.-T. Martinez-Cengotitabengoa, "Cognitive function in 6- to 12-year-old offspring of women with typel diabetes," Diabetic Medicine, vol. 28, no. 7, pp. 845-848, 2011.

[126] N. Barnea-Goraly, M. Raman, P. Mazaika et al., "Alterations in white matter structure in young children with type 1 diabetes," Diabetes Care, vol. 37, no. 2, pp. 332-340, 2014.

[127] O. Tolu-Kendir, N. Kiris, F. Temiz et al., "Relationship between metabolic control and neurocognitive functions in children diagnosed with type I diabetes mellitus before and after 5 years of age," The Turkish Journal of Pediatrics, vol. 54, no. 4, pp. 352361, 2012.

[128] A. L. McCall, "The impact of diabetes on the CNS," Diabetes, vol. 41, no. 5, pp. 557-570, 1992.

[129] G. Shehata and A. Eltayeb, "Cognitive function and eventrelated potentials in children with type 1 diabetes mellitus," Journal of Child Neurology, vol. 25, no. 4, pp. 469-474, 2010.

[130] B. O. Åsvold, T. Sand, K. Hestad, and M. R. Bjørgaas, "Cognitive function in type 1 diabetic adults with early exposure to severe hypoglycemia: a 16-year follow-up study," Diabetes Care, vol. 33, no. 9, pp. 1945-1947, 2010.

[131] A. M. Secrest, D. J. Becker, S. F. Kelsey, R. E. LaPorte, and T. J. Orchard, "Characterizing sudden death and dead-in-bed syndrome in type 1 diabetes: analysis from two childhood-onset type 1 diabetes registries," Diabetic Medicine, vol. 28, no. 3, pp. 293-300, 2011.

[132] P. P. Minnock and C. J. Howe, "Use of continuous glucose monitoring systems in children with type 1 diabetes," Critical Care Nursing Clinics of North America, vol. 23, no. 2, pp. 273290, 2011. 
[133] M. C. Samaan, A. Alassaf, J. DellaVedova, and M. Trisha, "Exercise-induced hypoglycemic hemiplegia in a child with type 1 diabetes: a rare find with multiple potential causative mechanisms," Case Reports in Medicine, vol. 2011, Article ID 529097, 3 pages, 2011.

[134] J. Lepercq, J. Lin, G. C. Hall et al., "Meta-analysis of maternal and neonatal outcomes associated with the use of insulin glargine versus NPH insulin during pregnancy," Obstetrics and Gynecology International, vol. 2012, Article ID 649070, 11 pages, 2012. 


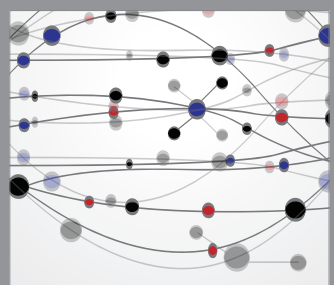

The Scientific World Journal
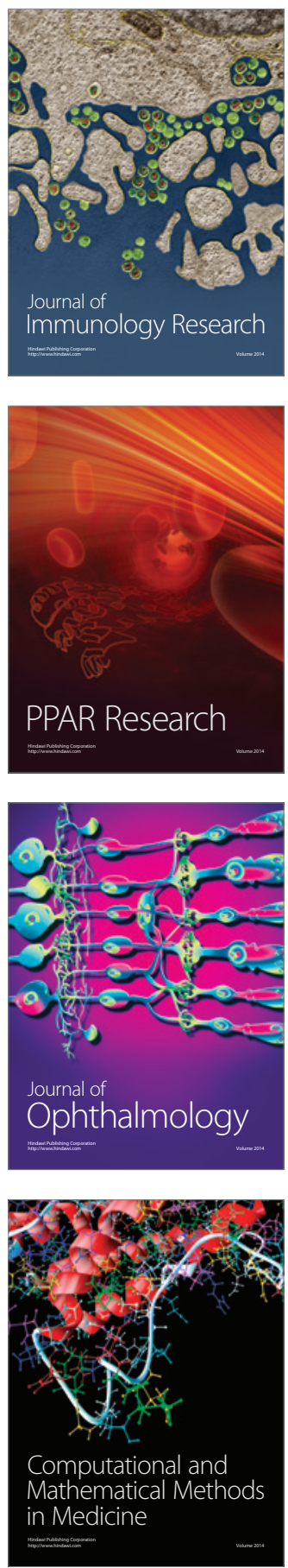

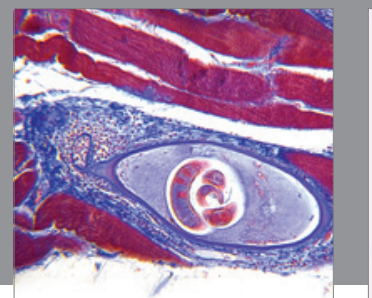

Gastroenterology

Research and Practice
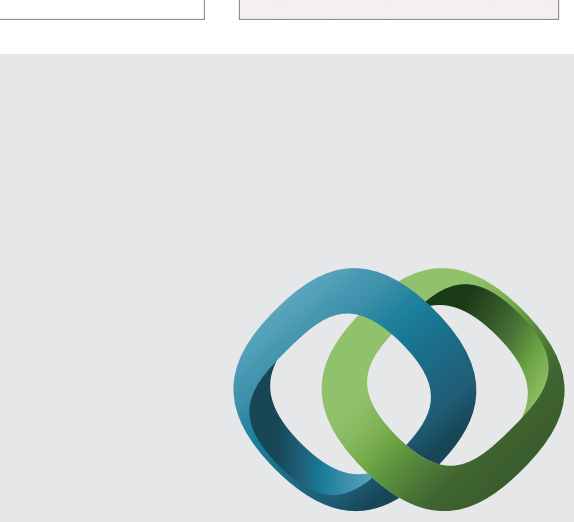

\section{Hindawi}

Submit your manuscripts at

http://www.hindawi.com
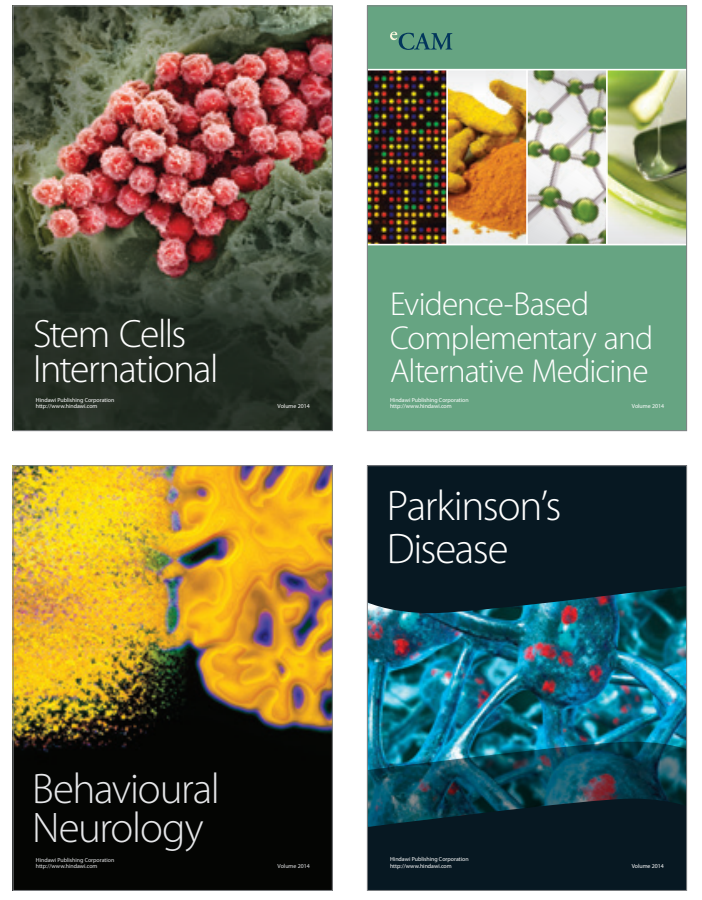
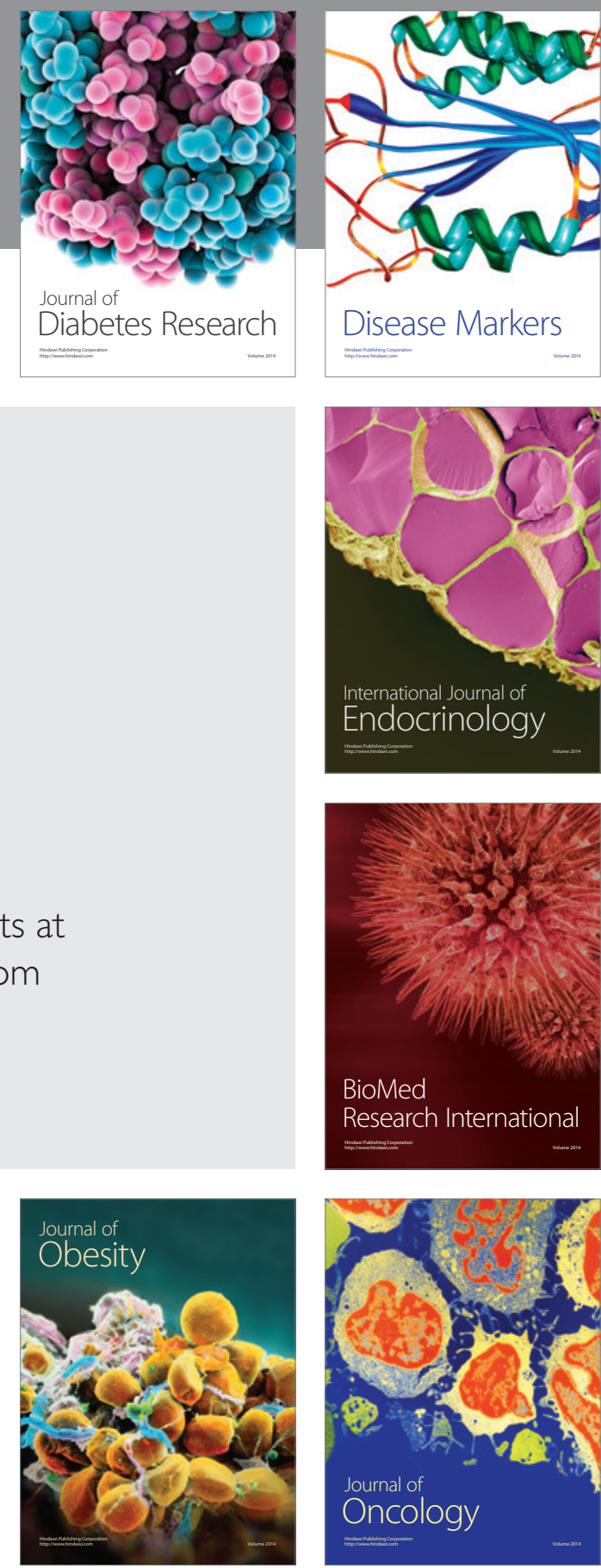

Disease Markers
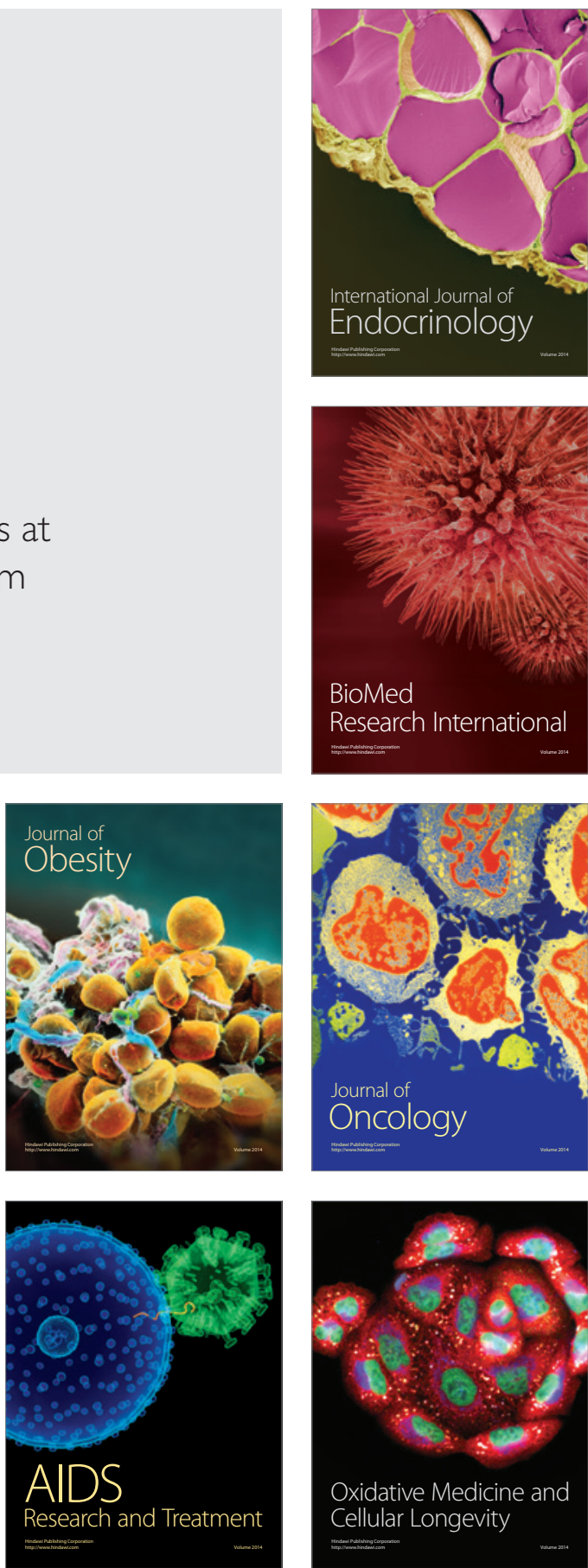